\title{
TECNOLOGIAS MÓVEIS E EDUCAÇÃO: UMA REDE CENTRADA NA APRENDIZAGEM
}

\author{
Caroline Birnfeldt \\ Carine Bueira Loureiro **
}

\begin{abstract}
Resumo: A ênfase dada à aprendizagem móvel, atrelada às condições neoliberais que conduzem os modos de viver deste tempo, e as políticas e orientações em nível global que produzem efeitos na educação brasileira compõem a rede que fomenta a problematização proposta neste trabalho. O objetivo desta pesquisa foi problematizar as verdades produzidas por práticas discursivas que enaltecem o uso de tecnologias móveis sem fio como ferramentas necessárias para a aprendizagem em políticas públicas e documentos emitidos por diferentes organizações. Para isso, por meio da metodologia da etnografia de rede, foram escrutinados nove documentos e construída uma rede que possibilitou a identificação das ligações entre os sujeitos e as diferentes agências que orientam e regulam políticas globais e que têm implicações na educação brasileira. A rede construída e os discursos extraídos dos documentos foram analisados com base na teorização foucaultiana e a partir dos conceitosferramenta de discurso e governamentalidade. Esse exercício possibilitou identificar que as diferentes agências estão relacionadas entre si, não só por meio dos sujeitos, mas também com os discursos propagados, que, ao enfatizarem a necessidade da aprendizagem móvel, produzem outros tipos de subjetividades, próprias deste tempo, que fazem reverberar a necessidade do investimento em aprendizagem como forma de empresariamento de si mesmo, eficiência e concorrência.
\end{abstract}

Palavras-chave: Educação. Etnografia de rede. Tecnologias móveis sem fio.

\section{Introdução}

A ênfase na utilização de tecnologias móveis sem fio (TMSF) na Educação Básica, como smartphones e tablets, está atrelada à presença constante destes artefatos na vida - nas formas de ser, relacionar-se, comunicar, agir - dos indivíduos na contemporaneidade. Não raro, estudantes deste nível de ensino portam estes recursos e deles fazem uso em sala de aula. O enaltecimento da utilização de recursos digitais na educação e a centralidade atribuída à aprendizagem - autoaprendizagem e aprendizagem ao longo da vida - são as principais justificativas imputadas à ideia de aprendizagem móvel, ou m-learning. Por aprendizagem móvel, entende-se "aprendizagem a qualquer hora e em qualquer lugar" (UNESCO, 2014, p.

\footnotetext{
* Acadêmica do Curso de Licenciatura em Matemática do Instituto Federal de Educação Ciência e Tecnologia do Rio Grande do Sul - campus Bento Gonçalves.

** Doutora em Educação (UNISINOS), orientadora, docente do Instituto Federal de Educação Ciência e Tecnologia do Rio Grande do Sul - campus Porto Alegre. Bolsista do CNPq / Brasil (167385/20178).
} 
8), em que o uso das TMSF se constitui como um recurso imprescindível. A discussão desenvolvida neste trabalho traz os achados da pesquisa intitulada Tecnologias móveis sem fio como ferramenta de aprendizagem ${ }^{l}$. Com base nos resultados obtidos, parte-se do entendimento de que é necessário problematizar as verdades produzidas por meio de discursos que enaltecem o uso de TMSF como ferramentas para o processo de aprendizagem.

A pesquisa supracitada teve como objetivo conhecer a rede por meio da qual são propagadas diretrizes que orientam a utilização de artefatos digitais na educação. A importância de desenvolver tal problematização está relacionada à ênfase atribuída, na atualidade, à aprendizagem móvel, bem como ao enaltecimento do uso das tecnologias digitais na educação. Loureiro e Lopes (2015), Barreto (2012) e Moreira (2007) demonstraram como a utilização de tecnologias digitais na educação está ligada às condições neoliberais, que conduzem nossos modos de viver, e às políticas em nível global, que produzem efeitos na educação brasileira. Isso reforça a ideia de que é relevante investigar, em políticas públicas e em documentos emitidos por organizações supranacionais e outras agências, como é disseminada a necessidade do uso das TMSF como recurso para a aprendizagem.

O conjunto de materiais empíricos a partir dos quais é desenvolvida a problematização, de teorização foucaultiana, aqui apresentada, é composto por nove documentos $^{2}$ emitidos por organismos supranacionais e por empresas privadas, pelas Diretrizes Curriculares Nacionais da Educação e pelo documento de proposta da Base Comum Curricular. A metodologia empregada no trabalho consiste na etnografia de rede (HOWARD, 2002) e em uma analítica a partir do conceito-ferramenta de discurso (FOUCAULT, 2009).

A etnografia de rede "consiste em um mapeamento da forma e do conteúdo das relações políticas em um campo particular" (HOWARD, 2002). Na pesquisa desenvolvida, utilizou-se como subsídio o livro Educação Global S. A., de Stephen Ball, que utiliza a rede como "um dispositivo analítico para pesquisar, descrever e visualizar relações de governança" (BALL, 2014, p. 32). Com o estudo dos documentos e por meio da etnografia de rede, foi possível encontrar recorrências dos sujeitos e das agências que os patrocinam e os formulam, realizar um mapeamento que estabelece as ligações entre os elementos e, dessa forma, compor

\footnotetext{
${ }^{1}$ Pesquisa desenvolvida com fomento do Edital PROPPI 009/2016 PIBIC/CNPq.

2 São eles: Inovações tecnológicas na educação: contribuições para gestores públicos, TIC Educação 2015, Inova Escola, O futuro da aprendizagem móvel, Diretrizes de políticas para a aprendizagem móvel, NMC Horizon Report, Juventude Conectada, Diretrizes Curriculares Nacionais da Educação e proposta da Base Comum Currricular.
} 


\section{\#tear}

a rede. Por meio da rede construída, observou-se que diferentes agências e sujeitos, comprometidos com diferentes instituições privadas, estão relacionados entre si e são os responsáveis, na atualidade, pela propagação de discursos que promovem a aprendizagem móvel como outro formato para o processo de aprendizagem.

Com a análise da rede formada e a partir do conceito-ferramenta de discurso (FOUCAULT, 2009), realizou-se uma analítica sobre os documentos com a intenção de identificar as verdades relativas ao uso de TMSF propagadas nestes documentos, que são emitidos por organizações supranacionais, empresas privadas ou mediante aliança entre estes dois tipos de instituições. Importa aqui destacar que, por discurso, se entende o que o excerto analisado, nesse caso, retirado do material empírico da pesquisa, diz na sua condição de "textualidade" (FISCHER, 2002, p. 65). Mais do que isso, os discursos "nunca podem se colocar por fora do acontecimento e, por isso, dos poderes que o acontecimento coloca em circulação" (VEIGA-NETO, 2014, p. 92).

A analítica empreendida na rede e nos materiais que subsidiaram o mapeamento demonstra que os discursos que advogam em prol das TMSF como ferramentas para aprendizagem evidenciam que, na atualidade, há um mercado global de educação com características neoliberais. Com isso, se quer enfatizar que, mais do que ações para qualificar o processo de ensino e de aprendizagem, o que está em jogo é a organização do campo de ação dos sujeitos, bem como a constituição destes em empresários de si mesmos. Dessa forma, evidencia-se a desoneração do Estado no processo de educação escolarizada. Mais do que isso, por meio do estudo realizado, percebeu-se que há estratégias de governamentalidade (FOUCAULT, 2010) neoliberal sendo operadas por meio dos documentos.

Por governamentalidade, entende-se as "ações distribuídas microscopicamente pelo tecido social" (VEIGA-NETO, 2002, p. 15) que têm o objetivo de conduzir as condutas da população. Queremos dizer que a rede, assim como os discursos presentes nos documentos que a compõem, produzem formas de ser, sentir, relacionar-se, comportar-se, conduzir a si mesmos e aos outros. Nesse caso, os documentos que propagam a utilização de TMSF na educação, ao mesmo tempo que são produzidos pelos sujeitos, também são produtores de comportamentos sociais, políticos e econômicos que forjam os próprios sujeitos.

Neste artigo, os achados da pesquisa serão problematizados em quatro seções. Na primeira, a partir da rede citada anteriormente, serão discutidas as ligações entre os sujeitos e as agências formuladoras dos documentos que formam a empiria da pesquisa. A segunda seção é destinada à análise e problematização dos discursos que reverenciam a utilização das TMSF na educação e que transferem a aprendizagem escolar para qualquer lugar e tempo. 


\section{\#tear}

Esse exercício não tem a intenção de excluir outras formas de aprendizagem, mas entende-se que a problematização tecida é necessária para que o rumo da educação possa ser repensado. Na terceira seção, pretende-se mostrar como os discursos analisados, além de prescreverem a aprendizagem em qualquer lugar e a individualização da aprendizagem, pontuam a necessidade de aprender por toda a vida, indo ao encontro do jogo da racionalidade neoliberal. Por fim, apresentam-se as considerações finais.

\section{A constituição de uma rede centrada na aprendizagem}

Conforme mencionado na introdução, a rede construída e apresentada na imagem a seguir (Figura 1) possibilitou que fossem verificadas ligações entre os sujeitos e as agências que patrocinam e elaboram os documentos que formam o material empírico da pesquisa aqui problematizada. A presença de empresas privadas nas diretrizes que relatam a importância do uso de tecnologias móveis sem fio na educação reforça o que Stephen J. Ball afirma em entrevista: "estamos assistindo a uma enorme participação do setor privado na educação pública” (ROSA, 2013, p. 460).

Figura 1: Rede de sujeitos e agências que prescrevem a utilização de TMSF na educação.

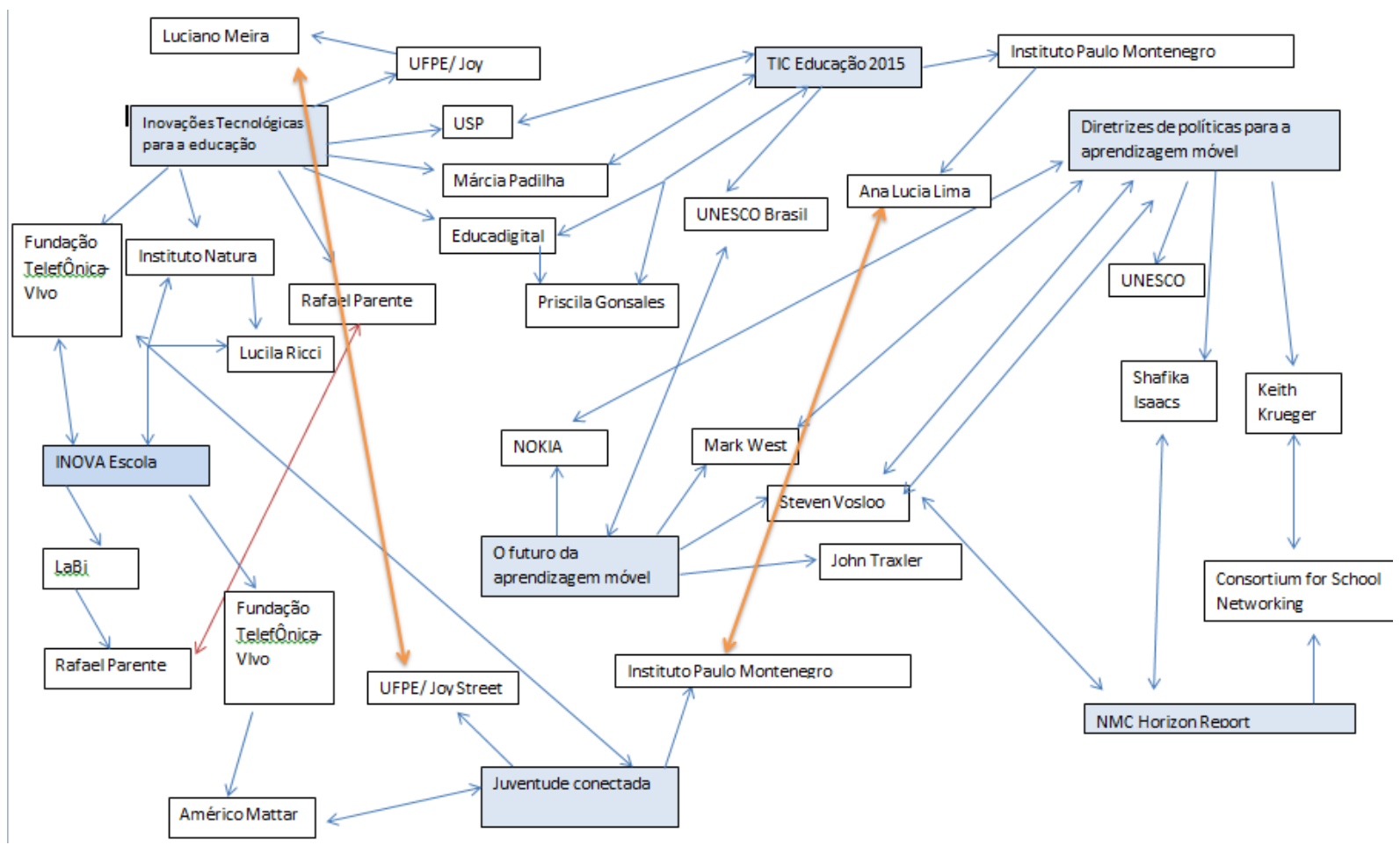

Fonte: autoras do artigo.

De acordo com o percurso metodológico apresentado na seção anterior, o conjunto de materiais que formam a empiria da pesquisa, além dos documentos emitidos por organizações 
supranacionais e empresas privadas, é composto por políticas públicas que relatam a necessidade de tecnologias digitais na educação e orientam sua incorporação; são elas: Diretrizes Curriculares Nacionais da Educação e o documento de proposta da Base Comum Curricular. Na rede elaborada e analisada, não são referenciados esses dois documentos porque neles não são citados sujeitos nem agências. No entanto, os discursos propagados por meio deles reproduzem o que é difundido nos documentos que compõem a rede. Sendo assim, ao prescreverem orientações para escolas e professores usarem tecnologias digitais na educação, com a justificativa de que "as novas tecnologias constituem, cada vez mais, uma condição essencial para que a pessoa saiba se posicionar frente aos processos e inovações que a afetam" (BRASIL, 2013, p. 26), esses documentos acabam repercutindo a mesma lógica dos outros documentos analisados. Nessa linha, os documentos que alicerçam a Educação Básica brasileira acabam por fazer reverberar a lógica empresarial (e neoliberal) disseminada pela aliança entre organismos supranacionais e empresas privadas. Os discursos dos documentos serão apresentados ao longo do texto, mas cabe pontuar aqui, muito brevemente, que eles constituem diretrizes globais que orientam a utilização de TMSF na educação.

A seção seguinte é dedicada à análise discursiva, discutindo-se a centralidade atribuída à aprendizagem nos documentos considerados. Além disso, serão problematizadas a ênfase de aprender em qualquer lugar e a individualização da aprendizagem, que são decorrentes dessa centralidade.

\section{Além da rede, os discursos: aprender em qualquer lugar}

Os documentos que prescrevem orientações para a utilização de TMSF na educação reforçam que esses dispositivos são "ferramentas riquíssimas e facilitadoras para a educação" (FUNDAÇÃO TELEFÔNICA VIVO, 2016, p. 77) e permitem que a "educação responda às demandas do século XXI" (TPE, 2014, p. 3). O anseio por uma mudança na educação é enaltecido pela presença das tecnologias como uma solução, na crença de que esses recursos “despertam o interesse do aluno, que redescobre o prazer de aprender" (TPE, 2014, p. 5). Dessa forma, o caráter sedutor das TMSF assume o papel de responsável por alterar, de certa maneira, o rumo da educação.

A aposta na utilização de TMSF na educação expressa em documentos que orientam e incentivam esses artefatos pontua a centralidade da aprendizagem no processo educativo. Em especial, a importância da aprendizagem móvel é enfatizada, de modo que "qualquer lugar pode interagir com a aprendizagem, que não acontece só no espaço contornado por quatro paredes" (FUNDAÇÃO TELEFÔNICA VIVO, 2016, p. 108). No contexto dos documentos 


\section{\#tear}

analisados, é fundamental que o sujeito aprenda independentemente do lugar, e o processo de aprendizagem, que antes ficava a cargo da escola, é transferido para as mãos do próprio indivíduo. Com efeito, ao descrever-se esse deslocamento, não se tem a intenção de desconsiderar as aprendizagens que acontecem em outros lugares, mas de marcar que agora o indivíduo é o responsável pela sua aprendizagem. Esse fenômeno não só destitui a escola enquanto instituição responsável por este processo, como também desresponsabiliza o Estado de garantir as condições necessárias para a manutenção de um espaço e tempo próprios e adequados para o processo de ensino e de aprendizagem. Por esses motivos, entende-se como necessária a problematização tecida, pois um espaço e tempo coletivos para que ocorra a aprendizagem promovem a democratização do saber, conforme abordado por Masschelein e Simons (2014), assim como conhecimentos específicos que permitam um uso adequado e crítico das tecnologias.

$\mathrm{Na}$ mesma esteira, ao festejar a ideia de que os alunos podem aprender por meio das TMSF "em qualquer hora” (YOUNG, 2016, p. 55) e que é necessário "ampliar os espaços de aprendizagem para além da sala de aula e dos muros da escola" (FUNDAÇÃO TELEFÔNICA VIVO, 2016, p. 101), entende-se, equivocadamente, que aprender é algo natural e que pode ocorrer fora do espaço e tempo da escola. Com essa mudança, como já problematizado por Loureiro (2015) e Barreto (2012), o papel do professor também é alterado, e este assume a condição de "mentor ou tutor" (FUNDAÇÃO TELEFÔNICA VIVO, 2016, p. 139), deixando de ser o responsável pelo ensino de saberes específicos e passando a ser o "orientador do percurso formativo dos alunos e mediador do seu processo de aprendizagem" (TPE, 2014, p. 6). Nessa lógica, os discursos que afirmam a urgente necessidade da utilização de TMSF na educação conduzem os indivíduos a acessarem e a estarem sempre acessíveis, pois, ao reiterarem que a aprendizagem deve acontecer em todos os momentos do dia, independentemente do lugar, afirmam que o uso de TMSF é um recurso imprescindível, uma vez que, talvez equivocadamente, exclui a necessidade de os indivíduos estarem na escola.

Trazendo-se essa problematização, não se tem a intenção de negar as potencialidades que os recursos digitais podem proporcionar ao processo de ensino e de aprendizagem. O que se quer é marcar que a aprendizagem não é um processo natural e simplificado e que ela requer, em muitos casos, a condução pedagógica (ENZWEILER, 2017) exercida pelo professor. O que se quer dizer é que é o "trabalho minucioso do professor pelo seu olhar recorrente aos avanços, aos percalços e às dificuldades que cada aluno possa apresentar" 
(ENZWEILER, 2017, p. 47) que torna o processo de aprendizagem, no ambiente escolar, algo único e irreproduzível.

De outra forma, ao incentivarem que a aprendizagem aconteça em qualquer lugar, os documentos que orientam a utilização de TMSF produzem uma responsabilização individualizada, pois, nesse contexto, é o indivíduo, munido da tecnologia, quem deve dar conta (sozinho) desse processo. O enaltecimento das TMSF para a aprendizagem propaga a ideia de que os recursos digitais sem fio permitem "que cada aluno aprenda no seu ritmo e do seu jeito" (TPE, 2014, p. 5) e de que os alunos possuem "liberdade para decidir o que, como e quando aprender" (YOUNG, 2016, p. 18). Colocado de outra maneira, tais discursos desconsideram a intencionalidade pedagógica (ENZWEILER, 2017) presente na educação escolarizada.

Enzweiler (2017) descreve o enfraquecimento da intencionalidade pedagógica devido ao "processo de esmaecimento do ensino como um efeito da exacerbação da aprendizagem e sua relação com os caminhos individuais" (ENZWEILER, 2017, p. 44), como se "os sujeitos pudessem aprender sem necessariamente precisar de intervenções” (ENZWEILER, 2017, p. 45). A autora defende que, com as intervenções pedagógicas, "os sujeitos podem avançar autonomamente em seus modos de aprender, não restringindo suas aprendizagens aos seus repertórios pessoais e individuais, mas partilhando com outros" (ENZWEILER, 2017, p. 46). Entende-se que, embora as justificativas apontem para o caráter onipresente das TMSF, que promovem a aprendizagem em qualquer tempo e lugar, a tecnologia, por si só, não é suficiente para que a aprendizagem baseada na condução ocorra, levando em conta que outras formas de aprendizagens possam ser viabilizadas também. A presença do professor, enquanto sujeito que conduz o processo de ensino, é essencial para que a aquisição de conhecimentos específicos aconteça, porque essa forma de condução está pautada na intencionalidade pedagógica, que caracteriza a escola como um lugar em que o conhecimento é compartilhado - ao contrário da aprendizagem defendida nos documentos, determinada apenas pela intencionalidade do dispositivo.

Além do esmaecimento do ensino situado na intencionalidade pedagógica, essa individualização da aprendizagem segue as regras do jogo da racionalidade neoliberal, pois, ao pontuarem que "aprender é um modo de vida" (YOUNG, 2016, p. 30), os discursos conduzem os sujeitos a assumirem para si mesmos a necessidade de aprender e de investir em si próprios. Nos documentos analisados, é recorrente a defesa da aprendizagem em qualquer lugar, e a individualização dessa aprendizagem está atrelada à ideia de aprendizagem permanente, ou de aprendizagem ao longo da vida, e às respectivas habilidades necessárias 


\section{\#tear}

para isso. A próxima seção é dedicada à problematização das justificativas que favorecem a constituição de um sujeito empresário de si mesmo.

\section{Habilidades para pertencer a este tempo: formação de um sujeito aprendiz permanente}

Conforme dito na seção anterior, os discursos que propagam a utilização de TMSF parecem reduzir a função da escola a um espaço de socialização e a do docente, antes um profissional responsável por ensinar conteúdos específicos, ao monitoramento da aprendizagem. Dessa maneira, o professor, a educação escolarizada e também o Estado deixam de ocupar centralidade no processo de ensino e aprendizagem. Com isso, a lógica neoliberal faz-se presente ao promover a constituição de sujeitos empresários de si mesmos, que assumem como condição de participação nos modos de vida da atualidade a importância da aprendizagem ao longo da vida, sob a justificativa de que, "no mundo ideal, a habilidade de aprender deve ser uma das mais significativas e fundamentais que se adquire na escola" (YOUNG, 2016, p. 26). Nessa linha de pensamento, segundo Ball (2013), aprendizagem ao longo da vida, ou permanente, mais do que aprender durante toda a vida, refere-se a estratégias de governamentalidade que, operadas de diversas maneiras, produzem um tipo de sujeito, o aprendiz ao longo da vida. Esse sujeito precisa assumir para si mesmo a necessidade de aprender sempre.

A função da escola, então, passa a ser "formar sujeitos com habilidades e competências para gerar seu próprio emprego e suas condições de consumir, concorrer, ou seja, sujeitos participativos da vida da atualidade” (LOUREIRO, 2013, p. 115). A ênfase na aprendizagem em qualquer lugar, na individualização da aprendizagem e na aprendizagem ao longo da vida está apoiada na necessidade de formar habilidades para que o sujeito se constitua como um empresário de si mesmo, conforme estamos problematizando aqui. Essa justificativa fortalece a ideia de que "aprender a aprender, dentro e fora da escola, é uma tarefa que cada ser humano terá de realizar para o resto da vida" (YOUNG, 2016, p. 10). Além disso, um sujeito capaz de aprender que possua "flexibilidade, a aptidão para resolver problemas, se comunicar, liderar, trabalhar em equipe e estar sempre aprendendo" (TPE, 2014, p. 3) tem as características necessárias para pertencer a este tempo. Os discursos presentes nos documentos elencados parecem reverenciar um sujeito empreendedor e competitivo que entende a necessidade de aprender ao longo da vida. Essas características estão calcadas na racionalidade neoliberal que regulam a educação. Conforme Avelino (2014, p. 1), 
No (neo)liberalismo se dá algo bastante diverso: não é o indivíduo que pensa sua conduta e, com esse gesto reflexivo, se fortalece enquanto sujeito de vontade; ao contrário, ele é pensado: objetivado pelas verdades da economia que estruturarão sua liberdade, isto é, seu campo de ação, para construí-lo como sujeito econômico.

Por isso, investir em aprendizagem ao longo da vida para constituir um indivíduo capaz de aprender em qualquer lugar e tempo parece ser lucrativo. Ao afirmarem que os estudantes, nativos digitais, "aprendem a receber informação com rapidez, gostam do processo paralelo, de realizar várias tarefas ao mesmo tempo" (BRASIL, 2013, p. 25), e que "a escola é chamada a considerar as potencialidades desses recursos tecnológicos" (BRASIL, 2016, p. 50) para que os alunos aprendam a "liderar, empreender e aprender continuamente" (BRASIL, 2016, p. 491), as políticas públicas brasileiras incorporam a mesma lógica do neoliberalismo.

A constituição de um sujeito empresário de si mesmo, na lógica da governamentalidade neoliberal, está ligada ao dever de investir em si mesmo, para que possa ter condições de concorrer e competir. A justificativa que sustenta essa lógica nos documentos analisados, valoriza a aprendizagem móvel, e sustenta o surgimento do sujeito capaz de aprender sempre e em todo lugar. Nos discursos analisados, as defesas citadas desconsideram a intencionalidade pedagógica do professor.

\section{Considerações finais}

Com a rede construída e a analítica desenvolvida sobre os documentos com o subsídio da ferramenta de discurso, observou-se que os documentos estão relacionados não somente por meio dos sujeitos e agências responsáveis por sua elaboração, mas também mediante os discursos propagados internacionalmente que se assemelham com os discursos propagados no contexto nacional. A ênfase na aprendizagem, autoaprendizagem e aprendizagem permanente e a necessidade de formar indivíduos participativos, que sejam dotados das habilidades para participar da economia, que entendam a necessidade de investir em si mesmos e de aprender ao longo da vida, estão destacadas em todos os documentos. Isso demostra que, na atualidade, há um mercado global de educação que se consolida e se propaga mundialmente com características neoliberais.

Percebeu-se que há ações de governamentalidade neoliberal sendo operadas nos discursos que reverenciam um sujeito empresário de si mesmo que entende a necessidade de concorrer e competir; à medida que esse indivíduo assume o risco de investir em si mesmo e 


\title{
\#tear
}

como empresa, ele se coloca à disposição do mercado. Assim, quando os documentos analisados prescrevem a utilização de TMSF na educação como forma de fomentar a aprendizagem ao longo da vida e em qualquer lugar, acabam favorecendo o esvaziamento da educação escolarizada. Esse esvaziamento consiste na valorização da aprendizagem móvel, da aprendizagem ao longo da vida e da autoaprendizagem, em detrimento da intencionalidade pedagógica exercida pelo professor.

É inegável que a utilização de artefatos digitais por alunos da Educação Básica é frequente, inclusive nas escolas. Portanto, cabe retomar que em nenhum momento a intenção da escrita foi criticar ou proibir a utilização das TMSF na educação. Da mesma forma, não se tentou negar as potencialidades desses dispositivos. Muito pelo contrário, acredita-se que eles podem colaborar para o processo de ensino e aprendizagem escolar. Porém, ao contrário do que se propaga nos documentos elaborados, o dispositivo não pode substituir o professor nem os conhecimentos específicos que são ensinados na escola. Cabe destacar novamente que outras aprendizagens podem ocorrer fora da escola e com o uso dos artefatos tecnológicos; no entanto, o professor é necessário enquanto sujeito que ensina, desafia os alunos para que a aprendizagem de conhecimentos próprios da escola aconteçam e cria condições para que o aluno desenvolva outras coisas. É com a intencionalidade pedagógica exercida pelo professor que o aluno consegue ir além de seus limites e, por exemplo, programar algum aplicativo em seu smartphone. O dispositivo, por si só, não dá conta de toda a complexidade que acontece na escola.

\section{MOBILE TECHNOLOGIES AND EDUCATION: A NETWORK BASED IN LEARNING}

\begin{abstract}
The emphasis given to mobile learning, coupled with the neoliberal conditions that lead to the lifestyle of this time, and the policies and guidelines at a global level that produce effects in Brazilian education make up the network that foments the problematization proposed in this work. The objective of this research was to problematize the truths produced by discursive practices that overvalue the use of mobile wireless technologies as necessary tools for learning in public policies and documents issued by different organizations. Therefore, through ethnography methodology of the network, nine documents were scrutinized and a network was created that made it possible to identify the links between the subjects and the different agencies that guide and regulate global policies and that have implications for Brazilian education. The constitute network and the discourses extracted from the documents were analyzed based on the Foucaultian theorization and from the concepts-tools of discourse and governmentality. This exercise made it possible to identify that the different agencies are interrelated not only through the subjects, but also with the propagated discourses, that emphasizing the need for mobile learning, and produce other kinds of subjectivities, typical of this time, that reverberate the need of investment in learning as a form of entrepreneurship, efficiency and competition.
\end{abstract}




\section{\#tear}

Keywords: Education. Ethnography of network. Mobile technologies.

\section{Referências}

AVELINO, Nildo. Foucault, Governamentalidade e o Neoliberalismo. 2014. Disponível em:

$<$ http://www.cchla.ufpb.br/ocs2.3.6/index.php/estudosfoucaultianos/estudosfoucaultianos/pap er/download/59/63>. Acesso em: 18 jan. 2017.

BALL, Stephen. Aprendizagem ao longo da vida, subjetividade e a sociedade totalmente pedagogizada. In: Educação. Porto Alegre, v. 36, n. 2. 2013. p. 144-155. Dossiê Biopolítica, governamentalidade, educação. Disponível em: <http://revistaseletronicas.pucrs.br/ojs/index.php/faced/article/view/12886/9446>. Acesso em: 26 out. 2016

BALL, Stephen. Educação global S. A.: novas redes políticas e o imaginário neoliberal. Ponta Grossa: Editora UEPG, 2014.

BARRETO, Raquel Goulart. A recontextualização das tecnologias da informação e da comunicação na formação e no trabalho docente. In: Educação \& Sociedade. Campinas, v.33, n.121. Out/Nov. 2012. p.985-1002.

BRASIL. Diretrizes Curriculares Nacionais Gerais da Educação Básica/ Ministério da Educação. Secretaria de Educação Básica. Diretoria de Currículos e Educação Integral. Brasília: MEC, SEB, DICEI, 2013. Disponível em: <http://portal.mec.gov.br/docman/julho2013-pdf/13677-diretrizes-educacao-basica-2013-pdf/file>. Acesso em: 24 jan. 2017.

BRASIL. Base Nacional Comum Curricular (Proposta Preliminar)/ Ministério da Educação. Brasília: MEC, 2016. Disponível em: < http://movimentopelabase.org.br/wpcontent/uploads/2016/05/BNCC-BOOK-WEB.pdf>. Acesso em: 24 jan. 2017.

ENZWEILER, Deise Andréia. Intencionalidade pedagógica: relações entre ensinar e aprender. In: LOUREIRO, Carine Bueira; KLEIN, Rejane Ramos (org.). Inclusão e aprendizagem: contribuições para pensar as práticas pedagógicas. Curitiba: Appris, 2017.

FISCHER, Rosa Maria Bueno. Verdades em suspenso: Foucault e os perigos a enfrentar. In: COSTA, Marisa Vorraber. Caminhos investigativos II: outros modos de pensar e fazer pesquisa em educação. Rio de Janeiro: Lamparina editora, 2002, p. 49-71.

FOUCAULT, M. Arqueologia do saber. 7 ed. São Paulo: Forense Universitária, 2009

FOUCAULT, Michel. Governamentalidade. In: Ditos e escritos IV. Rio de Janeiro: Forense Universitária, 2010. p. 281-305.

FUNDAÇÃO TELEFÔNICA VIVO. Inova escola: práticas para quem quer inovar na educação/ Fundação telefônica Vivo. - São Paulo (SP): Fundação Telefônica Vivo, 2016. Disponível em: <http://fundacaotelefonica.org.br/wp-content/uploads/pdfs/INOVAESCOLA.pdf >. Acesso em: 06 dez. 2016. 
HOWARD, Philliphe N. Network ethnography and the hypermedia organization: new media, new organizations, new methods. In: New media and Society, v. 4, n. 4, p. 550-74, 2002.

LOUREIRO, Carine Bueira. Inclusão digital e governamentalidade. In: FABRIS, Elí T. Henn; KLEIN, Rejane Ramos (org). Inclusão e Biopolítica. Belo Horizonte: Autêntica Editora, 2013.

LOUREIRO, Carine Bueira. Inclusão digital na educação: reconfigurações das funções docentes e discentes. In: HATTGE, Morgana Domênica.; KLEIN, Rejane Ramos. (Orgs) Diferença e inclusão na escola. Curitiba: CRV, 2015.

LOUREIRO, Carine Bueira. LOPES, Maura Corcini. A promoção da inclusão digital e a constituição do Homo oeconomicus accessibilis. In: LOUREIRO, Carine Bueira; LOPES, Maura Corcini (Orgs.). Dossiê In/Exclusão digital e educação. Educação, v. 38, n. 3, p. 329339, set/dez 2015.

MASSCHELEIN, Jan; SIMONS, Maarten. Em defesa da escola: uma questão pública. Belo Horizonte: Autêntica, 2014.

MOREIRA, Antônio Flávio; KRAMER, Sonia. Contemporaneidade, educação e tecnologia. In: Educação e Sociedade. Campinas, v. 28, n.100. Out. 2007. p. 1037-1057.

ROSA, Sanny Silva da. Entrevista com Stephen J. Ball - Privatizações da educação e novas subjetividades: contornos e desdobramentos das políticas (pós) neoliberais. Rev. Bras. Educ., Rio de Janeiro, v. 18, n. 53, p. 457-166, Jul. 2013. Disponível em: < http://www.scielo.br/scielo.php?script=sci_arttext\&pid=S1413-24782013000200012>. Acesso em: 14 jan. 2017.

ORGANIZAÇÃO DAS NAÇÕES UNIDAS PARA A EDUCAÇÃO, A CIÊNCIA E A CULTURA - UNESCO. Diretrizes de políticas para a aprendizagem móvel. 2014. Disponível em: <http://unesdoc.unesco.org/images/0022/002277/227770por.pdf〉. Acesso em: 16 nov. 2016.

TPE, Todos pela Educação. Inovações tecnológicas na educação: contribuições para gestores públicos. 2014. Disponível em:

$<$ https://www.todospelaeducacao.org.br//arquivos/biblioteca/inovacoes_tecnologicas_na_edu cacao_constribuicoes_para_gestores_publicos.pdf >. Acesso em: 16 nov. 2016.

VEIGA-NETO, Alfredo. Coisas de governo. In: RAGO, Margareth; ORLANDI, Luiz B. L. \& VEIGA-NETO, Alfredo (org.). Imagens de Foucault e Deleuze: ressonâncias nietzschianas. Rio de Janeiro: DP\&A, 2002. p.13-34.

VEIGA-NETO, Alfredo. Foucault \& a Educação/ Alfredo Veiga Neto. 3. ed. - Belo Horizonte: Autêntica Editora, 2014.

YOUNG DIGITAL PLANET. Educação no século 21: tendências, ferramentas e projetos para se inspirar. Tradução: Daniele Mendes Sales. São Paulo: Fundação Santillana, 2016. Disponível em: <https://smartlab.me/baixe-gratis-nosso-livro-educacao-no-seculo-21/>. Acesso em: 06 dez. 2016. 